\title{
OHRRINGE MIT PENDILIEN AUS CÍFER-PÁC ${ }^{1}$
}

\author{
G A B R I E L F U S E K
}

\begin{abstract}
Earrings with Pendilia from Cífer-Pác. In one of the graves at the Avar Kaghanate Period graveyard, two earrings with pendilia characteristic of the Pre-Köttlach Horizon were found. Along with them was in the grave a necklace composed of typical Avar beads. The find dates back to the second half of the $8^{\text {th }}$ century, with an emphasis on its last quarter.
\end{abstract}

Keywords: Southwestern Slovakia, Early Middle Ages, earrings, beads.

Während der Ausgrabungen auf umfangreichem frühmittelalterlichem Gräberfeld in Cífer, Ortsteil Pác, Flur Nad mlynom I wurde ein Grab mit einem Paar von Ohrringen, die in unserem geographischen Milieu einzigartig sind, freigelegt. Die Fundstelle befindet sich im Niederungsteil der westlichen Slowakei (Abb. 1), im geomorphologischen Gebiet Trnavská tabula. Auf dem Gräberfeld aus dem 8.-9. Jh. wurden in Jahren 1971, 1972, 1975, 1979 und 1983 zusammen 119 Gräber untersucht, doch bisher ist es nicht vollständig freigelegt und auch nicht veröffentlicht (Fusek 2006, 27).

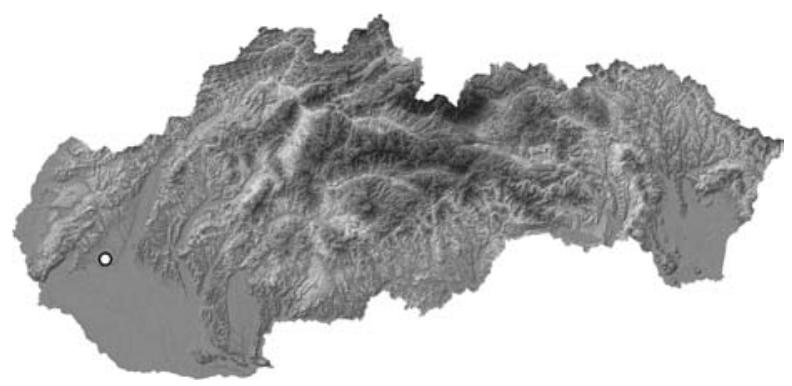

Abb. 1. Lage von Cífer-Pác auf der Karte der Slowakei.

\section{Grab 89 (Abb. 2)}

Die Grabgrube, ungefähr in Richtung W - O orientiert, wurde im Lössuntergrund in Tiefe $60 \mathrm{~cm}$ erkannt. Sie hatte einen rechteckigen Grundriss mit gerundeten Ecken, maximale Länge $123 \mathrm{~cm}$, Breite $54 \mathrm{~cm}$. Die Nordwand war vertikal, die anderen hatten sich mäßig schräg zum Boden in Tiefe $77-78 \mathrm{~cm}$ verengt. Längst der Nordwand befand sich in der unteren Hälfte ein niedriges, $10 \mathrm{~cm}$ breites flaches
Treppchen. Im Boden der Grabgrube befanden sich gleichlaufend mit ihren engeren Wänden sehr flache enge Aushöhlungen. Am Boden in Lage auf dem Rücken lag ein Skelett eines Kindes im Alter Infans I. $^{2}$ Dicht links und rechts neben dem Schädel lagen zwei Ohrringe $(1,2)$, am Hals eine Reihe von Perlen aus einer Halskette (3) und in der nordwestlichen Ecke einige Tierknochen.

1. Beschädigter Ringohrring mit zwei Pendilien, die aus Pseudokettchen und Blechplättchen zusammengesetzt sind. Dm. $13 \times 15 \mathrm{~mm}$, Drahtdicke 0,8 mm, erhaltene L. eines Pseudokettchens $17 \mathrm{~mm}$, des zweiten $11 \mathrm{~mm}$, L. der Plättchen 5 und 6 mm (Abb. 3: 1).

2. Beschädigter Ringohrring mit zwei Pendilien, die aus Pseudokettchen und Blechplättchen zusammengesetzt sind. Dm. 14 mm, Drahtdicke 0,8 mm, erhaltene L. der zwei Fragmente eines Pseudokettchens 9 und $6 \mathrm{~mm}$, des zweiten $15 \mathrm{~mm}$, L. der Plättchen 4 und 5 mm (Abb. 3: 2).

3. Halskette, zusammengesetzt aus sieben Glasperlen:

a) Schwarze Melonenkernperle mit Metallröhrchen in Öffnung, L. 15 mm (Abb. 3: 3a).

b) Beschädigte schwarze Melonenkernperle mit Metallröhrchen in Öffnung, L. $13 \mathrm{~mm}$ (Abb. 3: 3b).

c) Bruchstück einer schwarzen Melonenkernperle mit Metallröhrchen in Öffnung, L. $11 \mathrm{~mm}$ (Abb. 3: 3c).

d) Opake, mild türkisfarbige Melonenkernperle mit Metallröhrchen in Öffnung, L. 16 mm (Abb. 3: 3d).

e) Beschädigte opake, mild türkisfarbige Melonenkernperle mit Metallröhrchen in Öffnung, L. 16 mm (Abb. 3: 3e).

f) Opake, mild türkisfarbige fünffachgegliederte Perle mit Metallröhrchen in Öffnung, L. 12 mm (Abb. 3: 3f).

g) Opake, mild türkisfarbige vierfachgegliederte Perle mit Metallröhrchen in Öffnung, L. 10 mm (Abb. 3:3g).

Mit Rücksicht darauf, dass die Funde sehr korrodiert und zerbrechlich waren, entspricht ihr gegenwärtiger Stand nicht dem aus der Zeit ihrer

\footnotetext{
1 Der Beitrag entstand im Rahmen des Projektes VEGA 2/0088/20.

2 Bestimmung nach Baldovič 2003.
} 


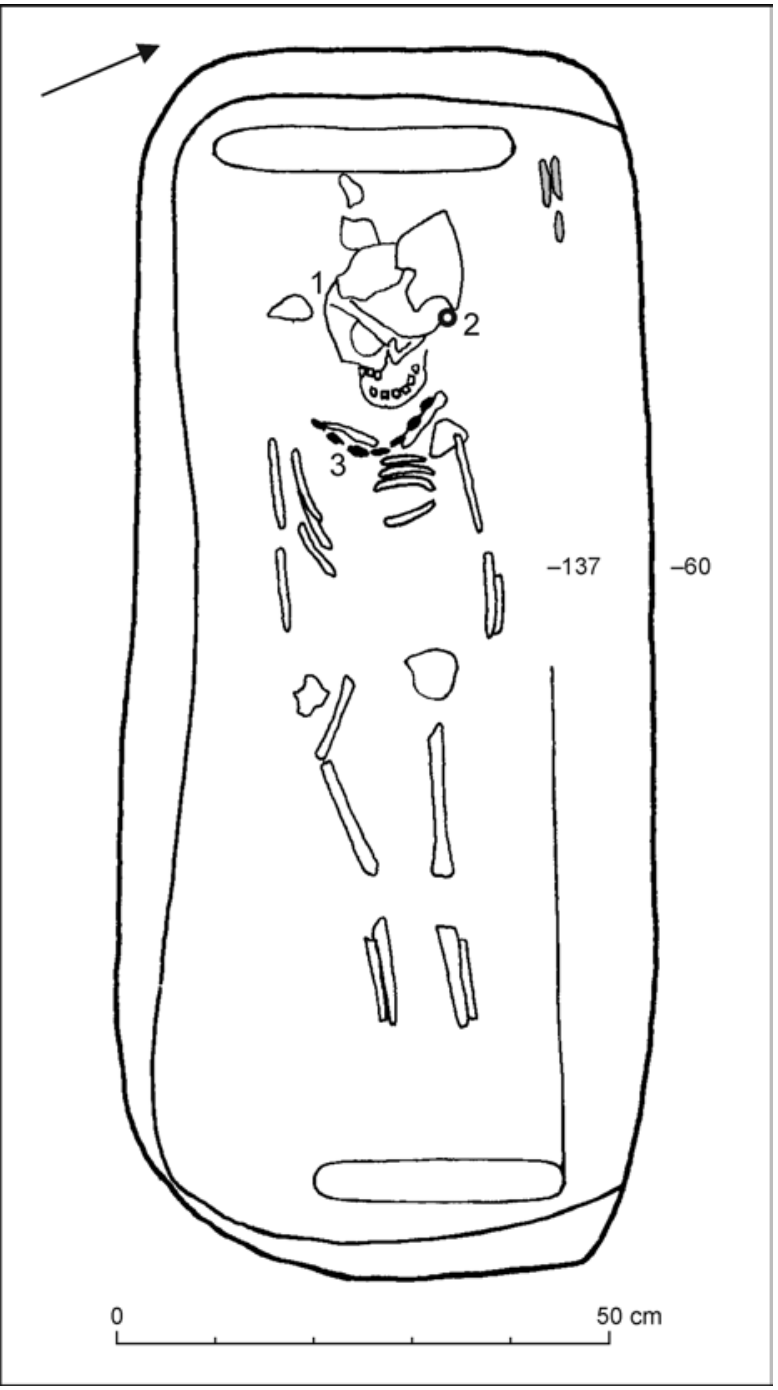

Abb. 2. Cífer-Pác. Zeichnung des Grabes 89. 1, 2-Ohrringe; 3 - Halskette; grau - Tierknochen.

Herausnahme aus dem Grab. Die Ohrringe wurden nach der Konservierung auf Glasplatten angeklebt, die Perlen im Verlauf von fast vierzig Jahren wurden teilweise verfallen. Deshalb befinden sich auf der Abbildung die Funde nicht nur im gegenwärtigen Stand, sondern auch im Zustand als ich sie gleich nach der Herausnahme in den Fundbericht gezeichnet habe. Um den Sicherheitswillen, die feinen Drähte der Anhänger aus den Ohrringen nicht zu beschädigen, habe ich mich nicht bemüht sie zusammenzulegen, deshalb habe ich sie damals nicht alle gezeichnet. Das Metall der Ohrringe wurde bisher mit einem Spektrometer nicht festgestellt, es kann sich um Silber oder Bronze handeln.

Das Gräberfeld in Cífer-Pác befindet sich am nördlichen Rand der awarischen Ökumene im Flussgebiet von Waag (Zábojník 1999, Karte 1). Es ist bisher bei uns die einzige bekannte Nekropole, die in der Zeit des Awarischen Kaganats gegründet wurde und Bestattungen in ihr kontinuierlich auch im 9. Jh. fortgesetzt wurden (Fusek 2006, 43-45). Das Ohrringpaar mit Pendilien ist jedoch in unserem Milieu ein fremdartiges Element in der materiellen Kultur aus den awarischen Gräberfeldern und auch aus der (vor)großmährischen Zeit. Mit ihm gefundene Melonenkernperlen sind charakteristischer Frauenschmuck der Awarenzeit (Čilinská $1975,87)$, typisch sind sie vor allem für ihre späte Stufe (Zábojník 2009, 60). Zusammen mit ihnen gefundene mehrfach gegliederte Perlen sind mit derselben Technologie des Glasaufwindens auf ein Metallröhrchen hergestellt, und sind aus gleichem opakem Glas gemacht. Zweifellos sind sie Bestandteil eines nicht ergänzten Colliers, deshalb kann man die Perlen zur Datierung benutzen. Die mehrfach gegliederten Perlen kommen in Gräbern der Abschlussetappen der Zeit des Awarischen Kaganats vor (Stufen SS III-IV; Zábojník 2009, 60). Z. B. die in Obid festgestellte Situation, wo die Bestattung in der Stufe SS III endete, kann andeuten, dass die Blütezeit ihres Tragens erst die Stufe SS IV ist, weil auf dem Gräberfeld nur eine einzige solche Perle gefunden wurde (Zábojník 2019, 91). Ähnliche Fundumstände mit der Datierung der mehrfach gegliederten Perlen in den jüngsten Zeitabschnitt der Bestattung sind auch aus weiteren Gräberfeldern bekannt (Čilinská 1966, 160, 161). Aus dem Gesichtspunkt der absoluten Datierung kann man Grab 89 anhand der Perlen in die Zeitspanne der Jahre 750-800 (825) datieren (absolute Datierung nach Zábojník 1991, 248). Eine Präzisierung in den letzten Viertel des 8. Jh. mit Übergriff in den Anfang des nächsten Jahrhunderts ist auch nicht ausgeschlossen.

Mit ähnlichen Ohrringen mit Pendilien hat sich vor einiger Zeit Š. Ungerman (2006, 356; 2016, 210, 211; 2018, 28-30) gründlich beschäftigt, deshalb werde ich die einzelnen analoge Funde nicht aufführen. Die Ohrringe aus Cífer-Pác unterscheiden sich von den bisher bekannten Exemplaren dadurch, dass der Ringbogen nicht von einer Öse abgeschlossen wird und der untere Ringbogen mit einem feinen Draht nicht umgewickelt ist. Das Pseudokettchen wurde auf den Bogen mit einer Schleife, gemacht durch seine Drähte, angebracht. Ähnlich ist auch ihr unterer Abschluss, der der Befestigung der Blechzierden diente. Ihre ursprüngliche Form konnte wegen der Korrosion nicht festgestellt werden. Variante Konstruktionsdetails haben keinen Einfluss auf die chronologische Position der Funde. Die Ohrringe von diesem Typ sind charakteristischer Frauenschmuck des Vor-Köttlach-Horizontes auf den Gebieten südlich der mittleren Donau und im Ostalpenraum. 


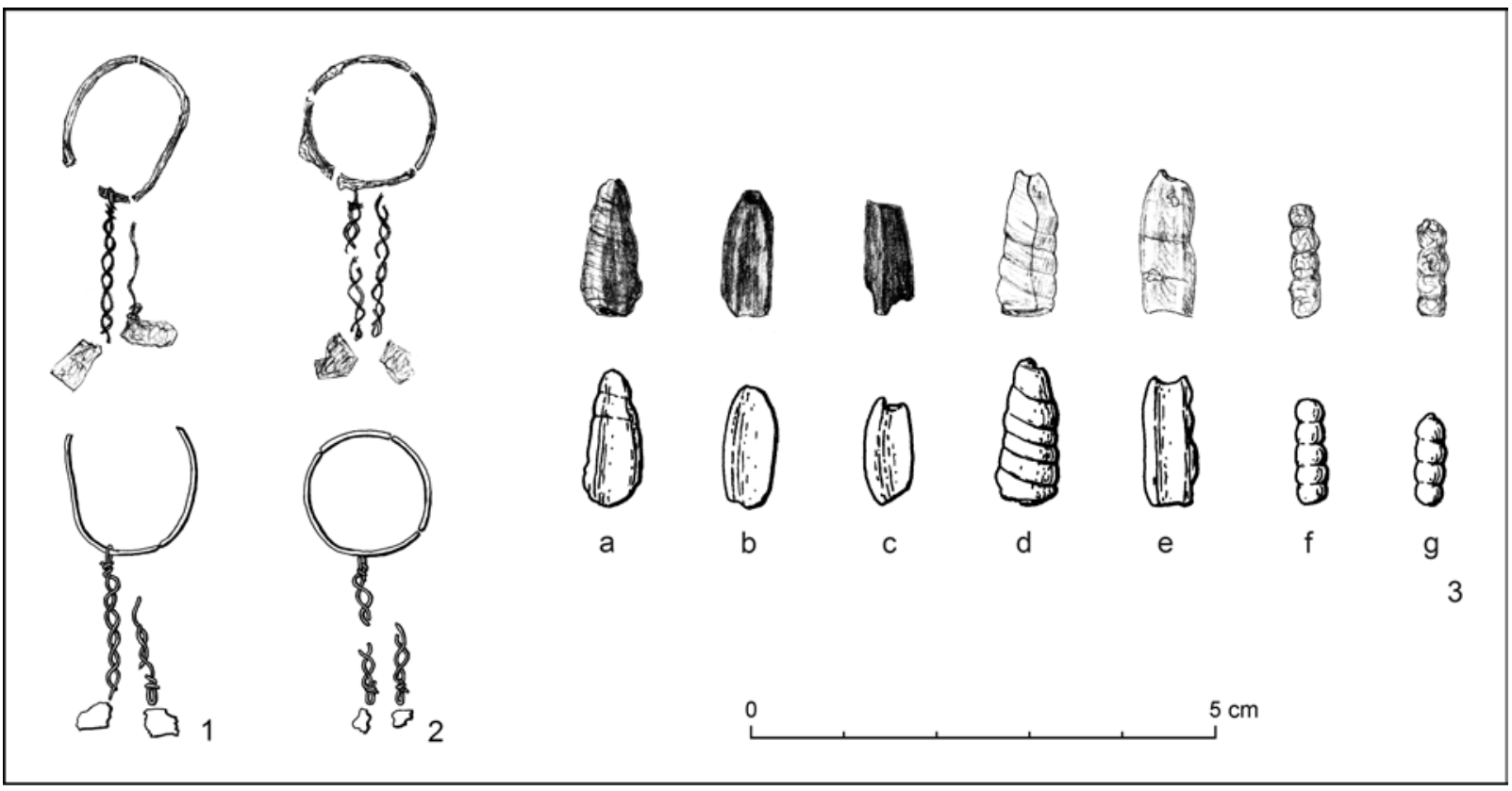

Abb. 3. Cífer-Pác. Funde aus Grab 89. Zeichnungen aus dem Jahr 1983 und gegenwärtiger Stand.

Der Fund der Ohrringe mit Pendilien in einem Grab, zusammen mit charakteristischen awarischen Perlen, bestätigt die Berechtigung von Ungerman's
Datierung dieser Art des Schmucks in die zweite Hälfte des 8. Jh. mit möglichem Akzent auf seinen letzten Viertel.

\section{LITERATUR}

Baldovič 2003 - M. Baldovič: Antropologický rozbor kostrového pohrebiska Cífer-Pác (okr. Trnava) z 8.-9. storočia n. l. Diplomová práca. Prírodovedecká fakulta Univerzity Komenského. Katedra antropológie. Bratislava 2003. Unpubliziert.

Čilinská 1966 - Z. Čilinská: Slawisch-awarisches Gräberfeld in Nové Zámky. Archaeologica Slovaca. Fontes VII. Bratislava 1966.

Čilinská 1975 - Z. Čilinská: Frauenschmuck aus dem 7.-8. Jahrhundert im Karpatenbecken. Slovenská archeológia 23, 1975, 63-96.

Fusek 2006 - G. Fusek: Výklenkové hroby na včasnostredovekom pohrebisku v Cíferi, časti Pác. Študijné zvesti AÚ SAV 39, 2006, 27-54.

Ungerman 2006 -Š. Ungerman: Tzv. předköttlašský horizont a počátky velkomoravského kostrového pohřbívání. Archaeologia historica 31, 2006, 351-369.

Ungerman 2016 - Š. Ungerman: Tzv. karantánské náušnice ve středním Podunají. Památky archeologické 107, 2016, $181-236$

Manuskript angenommen am 31. 5. 2021

Übersetzt von Lubomír Novotný

Abstract translated by Michal Holeščák
Ungerman 2018-Š. Ungerman: Frühmittelalterliche Schlaufenohringe mit Drahtanhängern oder Kettchen. In: F. Daim/ D. Heher/C. Rapp (Hrsg.): Menschen, Bilder, Sprache, Dinge. Wege der Kommunikation zwischen Byzanz und dem Westen 1: Bilder und Dinge. Studien zur Ausstellung „Byzanz \& der Westen. 1000 vergessene Jahre“. Mainz 2018, 9-43.

Zábojník 1991 -J. Zábojník: Seriation von Gürtelbeschlaggarnituren aus dem Gebiet der Slowakei und Österreichs (Beitrag zur Chronologie der Zeit des Awarischen Kagantas). In: Z. Čilinská (red.): K problematike osídlenia stredodunajskej oblasti vo včasnom stredoveku. Nitra 1991, 219-321.

Zábojník 1999 - J. Zábojník: Das Awarische Kaganat und die Slawen an seiner nördlichen Peripherie. Slovenská archeológia 47, 1999, 153-173.

Zábojník 2009 -J. Zábojník: Slovensko a avarský kaganát. Druhé prepracované a doplnené vydanie. Studia Archaeologica et Medievalia IX. Bratislava 2009.

Zábojník 2019 - J. Zábojník: Pohrebisko z obdobia avarského kaganátu v Obide. Archaeologica Slavaca Monographiae. Fontes XXVI. Bratislava - Nitra 2019.

PhDr. Gabriel Fusek, CSc.

Archeologický ústav SAV

Akademická 2

SK - 94921 Nitra

gabriel.fusek@savba.sk 
